Источник опубликования: Красинский В.B. Теоретические основы нормативного правового регулирования организации и проведения выборов в Российской Федерации // Конституционное и муниципальное право. М.: Юристь, 2003. № 1. С.13-16; www.krasinskiy.ru

\title{
Теоретические основы нормативного правового регулирования организации и проведения выборов в Российской Федерации.
}

В системе современного народовластия Российской Федерации важное место занимает политико-правовой институт выборов. Это обусловлено многофункциональным характером данного демократического института, позволяющего рассматривать выборы в качестве одной из основ конституционного строя России; в качестве высшей формы осуществления непосредственного народовластия; в качестве формы реализации конституционного права российских граждан участвовать в управлении делами государства как непосредственно, так и через своих представителей; и, наконец, в качестве формы реализации конституционного права избирать и быть избранными в органы государственной власти и органы местного самоуправления.

Сущность и значение выборов проявляется во множестве аспектов: они определяют формирование органов народного представительства, выступают средством активизации населения, устанавливают обратную связь между гражданами и выборными должностными лицами, содействуют развитию демократического правового государства в Российской Федерации.

Общественные отношения, которые затрагивают выборы, имеют важное значение для обеспечения стабильности конституционных основ политической системы России, воспроизводства и функционирования демократических институтов государственной власти и местного самоуправления, и, в связи с этим, объективно требуют правового упорядочения. Поэтому государство использует нормативное правовое регулирование организации и проведения выборов в Российской Федерации.

Научное исследование теоретических основ нормативного правового регулирования организации и проведения выборов представляется необходимым начать с разграничения категорий «правового» и «нормативного правового регулирования». В первую очередь обратимся к понятию правового регулирования организации и проведения выборов.

В юридической науке правовое регулирование традиционно рассматривается как процесс целенаправленного воздействия государства на поведение людей и общественные отношения с помощью норм права и других правовых средств. 
Отдельными авторами правовое регулирование понимается в узком и широком смысле ${ }^{1}$.

В узком смысле правовое регулирование представляет собой воздействие норм права, других специально-юридических средств на поведение людей и на общественные отношения в целях их упорядочения и прогрессивного развития.

Правовое регулирование в широком смысле - это разностороннее воздействие на общественные отношения всех правовых явлений, в т.ч. правовых идей, принципов правовой жизни общества, не воплощенных в юридические формы (законы, нормативные правовые акты, решения судебных органов).

Особого внимания заслуживает вопрос о соотношении правового регулирования и правового воздействия. Так, если исследовать понятия «регулирование» и «воздействие», то очевидна неидентичность этих терминов. Слово регулировать означает: (от лат. regulo приводить в порядок)

1. Подчинять определенному порядку, правилам; упорядочивать.

2. Воздействовать на работу механизма и его частей, добиваясь нужного протекания какого-либо процесса ${ }^{2}$. В свою очередь, термин «воздействие» означает влияние на что-либо при помощи определенной системы действий. ${ }^{3}$

Как видно, смысловая нагрузка у этих двух категорий близка, и даже частично совпадает, но, вместе с тем, не однозначна, поскольку понятие «воздействие» по своему объему более широкое, чем «регулирование».

В юридической литературе одни исследователи включают в правовое регулирование все виды воздействия права на сознание и поведение людей, другие выводят за его пределы идеологию, воспитание. В этом случае правовое регулирование будет охватывать правовое сознание, правовую культуру, механизм правового регулирования, правовые принципы, правотворческий процесс. ${ }^{4}$ Сторонники приведенной точки зрения фактически отождествляют правовое регулирование с правовым воздействием и под правовым регулированием понимают совокупность различных видов и форм влияния права на общественные отношения, на поведение и сознание людей. ${ }^{5}$

Большинство ученых - юристов придерживается мнения о более широком объеме понятия правового воздействия по сравнению с правовым регулированием. На взгляд автора, данный подход является наиболее удачным и обоснованным. Во-первых, предмет правового регулирования несколько уже предмета правового воздействия. В последний входят и такие экономические, политические, социальные отношения, которые правом не регулируются, но на которые оно, так или иначе распространяет свое влияние. Во-вторых, если правовое 
регулирование как специально-юридическое воздействие в любом случае связано с установлением конкретных прав и обязанностей субъектов, с прямыми предписаниями о должном и возможном, то правовое воздействие - не всегда. Тот или иной субъект может никогда не быть участником каких-либо отношений, не совершать каких-либо действий, предусмотренных нормами права. Однако его ознакомление с содержанием определенного закона оказывает влияние на его сознание, мировоззрение. В-третьих, правовое регулирование означает осуществление правовых норм через правоотношения, а правовое воздействие - необязательно. Правовое воздействие включает как регулирование с помощью определенной правовой нормы, так и другие правовые средства и формы влияния на поведение людей 6 .

Правовое регулирование основывается на предмете и методе правового регулирования. Предметом правового регулирования является определенный вид общественных отношений, который закрепляется соответствующей группой правовых норм. Рассматриваемые в настоящей статье общественные отношения, возникающие в процессе организации и проведения выборов и урегулированные соответствующими правовыми нормами, являются предметом избирательного права.

В свою очередь, правовые нормы, регулирующие порядок организации и проведения выборов, оказывают воздействие на общественные отношения в данной сфере посредством метода правового регулирования. Метод правового регулирования избирательного права сочетает элементы императивно-диспозитивных предписаний, что свойственно нормам практически всех отраслей права и, в силу этого, не обладает какой-либо спецификой.

Ocобое место в упорядочении общественных отношений, возникающих в процессе организации и проведения выборов, принадлежит нормативному правовому регулированию. Нормативное правовое регулирование имеет общеобязательный характер для субъектов права и распространяется на все общественные отношения определенного рода или вида. Согласно п.2 ст.1 Федерального закона от 12 июня 2002 года № 67-Ф3 «Об основных гарантиях избирательных прав и права на участие в референдуме граждан Российской Федерации», настоящий закон регулирует отношения, связанные с организацией и проведением выборов, имеет прямое действие и применяется на всей территории Российской Федерации. Достоинства нормативного правового регулирования состоят в том, чтобы ввести общественные отношения в рамки, приемлемые для всех членов общества, придать им определенную устойчивость, упорядоченность, независимость от произвола отдельных личностей. 
В ходе нормативного правового регулирования организации и проведения выборов государство устанавливает общие правила поведения, обязательные для всех участников избирательного процесса (например, правила составления списков избирателей, правила выдвижения и регистрации кандидатов (списка кандидатов), правила ведения предвыборной агитации и финансирования избирательной кампании).

Вместе с тем, нормативное правовое регулирование организации и проведения выборов не в состоянии учесть все разнообразие особенностей конкретных отношений и поэтому нуждается в дополнении его индивидуальным правовым регулированием.

Индивидуальное правовое регулирование осуществляется третьими субъектами, не являющимися участниками регулируемых отношений, или самими субъектами участниками отношений (саморегулирование). В первом случае субъектом индивидуального регулирования выступают государственные органы - суды, органы администрации, внутренних дел. Примером может служить решение суда или избирательной комиссии об отмене регистрации кандидата (ст. 76 Федерального закона «Об основных гарантиях избирательных прав и права на участие в референдуме граждан Российской Федерации»). Вторым видом индивидуального регулирования являются договоры (соглашения, контракты). Это распространенная форма саморегулирования, позволяющая учесть особенности конкретных отношений, интересы участников отношений на основе их свободного волеизъявления и взаимного согласия. Так, в соответствии с п.7 ст. 37 настоящего закона, кандидат, избирательное объединение, избирательный блок могут заключать с лицом, собирающим подписи избирателей, договор о сборе подписей.

Сочетание нормативного правового регулирования и индивидуального правового регулирования в процессе организации и проведения выборов необходимо, поскольку, взятые по отдельности, они сразу начинают демонстрировать свои «слабые стороны»: нормативное регулирование без индивидуального (без усмотрения) превращается зачастую в формализм, а индивидуальное без нормативного (без общих правил) - в произвол ${ }^{7}$. Если нормативное правовое регулирование призвано обеспечить стабильность и необходимое единообразие общественных отношений, ввести их в твердые рамки законности, то индивидуальное - учет конкретной обстановки, своеобразие каждой юридической ситуации.

Несмотря на то, что рассматриваемые виды правового регулирования носят взаимосвязанный характер и взаимно дополняют друг друга, следует четко разделять правовое регулирование, осуществляемое с помощью индивидуально-правовых актов, и нормативное правовое регулирование. 
Индивидуальное правовое регулирование представляет собой целенаправленное воздействие на конкретного субъекта права, осуществляемое с помощью индивидуального правового акта. В то время как нормативное правовое регулирование - это целенаправленное воздействие компетентного государственного органа на неопределенный круг лиц, осуществляемое с помощью правовых норм и обеспечивающее реализацию правовых предписаний путем установления субъективных прав, юридических обязанностей и мер ответственности за неисполнение соответствующих правовых норм. Между указанными видами правового регулирования существуют определенные различия.

Во-первых, индивидуальные правовые акты не содержат норм права.

Во-вторых, индивидуальные правовые акты принимаются только на основе норм права и являются актами применения норм права. К примеру, п.19 ст.28 Федерального закона «Об основных гарантиях избирательных прав и права на участие в референдуме граждан Российской Федерации» предусматривает, что избирательные комиссии могут привлекать граждан к выполнению работ, связанных с подготовкой и проведением выборов, по гражданско-правовым договорам. Указанные договоры принимаются на основе анализируемой нормы.

И, наконец, индивидуальные правовые акты, в отличие от нормативных актов, всегда обращены к конкретному субъекту права. Индивидуальным правовым актом будет являться решение избирательной комиссии о регистрации конкретного гражданина в качестве кандидата. С этого момента лицо приобретает права и обязанности, связанные со статусом кандидата.

В связи с ограниченностью объема настоящей статьи автор не рассматривает индивидуальное правовое регулирование в процессе организации и проведения выборов.

В плане раскрытия содержания нормативного правового регулирования необходимо исследовать смысловую нагрузку понятия «организация и проведение выборов». Представляется, что основные элементы организации выборов носят вспомогательный характер, в том или ином объеме обслуживают соответствующие стадии проведения выборов, в то время как собственно проведение выборов обеспечивает функциональную завершенность всей работы по подготовке к выборам. Организация и проведение выборов осуществляется в рамках избирательной кампании (т.е. начиная со дня официального опубликования решения о назначении выборов до дня представления избирательной комиссией, организующей выборы, отчета о расходовании средств соответствующего бюджета, выделенных на подготовку и проведение выборов) и призвана обеспечивать совершение установленных законом избирательных действий и избирательных процедур, 
гарантирующих реализацию и защиту конституционного права граждан России избирать и быть избранными в органы государственной власти и органы местного самоуправления ${ }^{8}$. Наиболее близким к «организации и проведению выборов» является понятие избирательного процесса. В широком смысле термин «избирательный процесс» совпадает с термином «избирательная кампания». В узком смысле «избирательный процесс» как формализованное явление включает установленную законом совокупность стадий, обеспечивающих его целостность и легитимность результатов выборов 9 .

Существующий в Российской Федерации процесс избрания органов государственной власти и местного самоуправления состоит из целого ряда самостоятельных стадий.

К числу обязательных стадий избирательного процесса относятся: назначение выборов; составление списков избирателей; образование избирательных округов, избирательных участков; формирование избирательных комиссий; выдвижение и регистрация кандидатов (списков кандидатов); финансирование; агитация при проведении выборов; голосование и определение результатов выборов. Факультативными стадиями являются проведение повторного голосования, повторных и дополнительных выборов.

Нормативное правовое регулирование организации и проведения выборов в Российской Федерации охватывает все стадии избирательного процесса выборов всех уровней.

Важным направлением разработки теоретических основ нормативного правового регулирования организации и проведения выборов является обстоятельное исследование системы правоотношений. Правоотношения в рассматриваемой сфере представляют собой универсальное средство трансформирования общих программ поведения, заложенных в нормах избирательного права, в плоскость субъективных прав и юридических обязанностей конкретных участников избирательного процесса.

Изучение правоотношений, возникающих в процессе организации и проведения выборов, свидетельствует о возможности разнообразных критериев и классификаций.

Правовые отношения, участником которых являются субъекты избирательного процесса, в зависимости от положения сторон и возможности выбора варианта поведения, можно разграничить на:

вертикальные правоотношения, которые представляют собой отношения власти подчинения. Примером могут служить отношения вышестоящих избирательных комиссий и должностных лиц, выступающих в качестве государственно-властных субъектов по отношению к нижестоящим избирательным комиссиям и подчиненным сотрудникам ${ }^{10}$; 
горизонтальные правоотношения, связывающие между собой избирателей-граждан России (в предусмотренных законом случаях - и иностранных граждан), избирательные объединения (блоки), зарегистрированных кандидатов, списки кандидатов, а также различные избирательные комиссии одного уровня соподчиненности. Эти отношения характеризуются равенством прав и обязанностей их участников.

Возможны и другие основания для классификации: по отраслям права (административно-правовые, уголовно-правовые и др.), по характеру регулируемых отношений (регулятивные и охранительные).

Вместе с тем, правоотношения, складывающиеся в процессе организации и проведения выборов, зависят не только от правового положения сторон в избирательном процессе, характера регулируемых отношений и иных факторов, но и обусловлены соответствующими правовыми нормами.

В структуре нормативного правового регулирования организации и проведения выборов правовые нормы важны не только потому, что они закрепляют основные гарантии реализации гражданами Российской Федерации избирательных прав, устанавливают прочную юридическую основу, детально и всесторонне определяющую поведение и деятельность участников общественных отношений, связанных с выборами органов и должностных лиц государства и местного самоуправления, на всех стадиях избирательного процесса, но и в связи с тем, что они позволяют понять и выразить суть нормативного регулирования.

Суть нормативного правового регулирования организации и проведения выборов заключается в том, чтобы посредством соответствующих правовых норм обязывать, запрещать или рекомендовать всем участникам избирательного процесса действия в интересах наиболее полной реализации гарантий избирательных прав и свобод граждан. Именно правовые нормы избирательного законодательства предоставляют определенные права и возлагают конкретные обязанности на участников общественных отношений, связанных с выборами.

Содержание нормативного правового регулирования организации и проведения выборов выступает как внутреннее состояние, характеризующее избирательный процесс. Выражением и способом существования содержания нормативного правового регулирования в данной сфере общественных отношений являются нормы права, детально регламентирующие стадии избирательного процесса ${ }^{11}$. В свою очередь, содержательная сторона организации и проведения выборов в Российской Федерации определяется поставленными законодателем целями нормативного правового регулирования. 
Основную цель нормативного правового регулирования можно определить как конечный ожидаемый результат, предполагаемое управомоченным на то органом состояние отношений, для достижения которого предлагается использование определенных правовых норм. Исходя из изложенного, целями нормативного правового регулирования организации и проведения выборов в РФ выступают: упорядоченность, прогрессивное развитие и преобразование общественных отношений, возникающих в процессе организации и проведения выборов. К сожалению, складывающаяся в Российской Федерации нормотворческая практика указывает на то, что зачастую целеполагание, лежащее в основе нормативного правового регулирования, определяется законодателем, исходя из особенностей конкретной общественно-политической обстановки в стране в определенный период времени, подменяется интересами тех политических сил и финансовопромышленных группировок, в руках которых находится государственная власть.

Таким образом, можно подвести определенные итоги настоящего исследования теоретических основ нормативного правового регулирования организации и проведения выборов в Российской Федерации.

В сфере организации и проведения выборов в Российской Федерации возникают разнообразные общественные отношения. Для того, чтобы целенаправленно воздействовать на их развитие и преобразование, государство использует правовые нормы. Процесс целенаправленного воздействия компетентных государственных органов на поведение людей и общественные отношения, складывающиеся в процессе организации и проведения выборов, с помощью норм права, путем установления субъективных прав, юридических обязанностей и мер ответственности, представляет собой нормативное правовое регулирование организации и проведения выборов в Российской Федерации.

Представляется целесообразным обозначить ряд ключевых проблем, важных для понимания теоретических основ нормативного правового регулирования организации и проведения выборов в Российской Федерации и их реализации в практике законотворческого процесса.

Первое. Для совершенствования нормативного правового регулирования в современных условиях большое значение приобретает проблема качества и юридической техники издаваемых нормативных правовых актов. Более того, возникают парадоксальные ситуации, когда даже тщательно проработанный и принятый текст закона в официальном опубликовании существенно отличается от оригинала ${ }^{12}$.

Второе. С позиций теории права актуальной является проблема разграничения предметов ведения и пределов нормативного правового регулирования в рассматриваемой 
сфере. В связи с этим представляется необходимым более четко законодательно закрепить предметы нормативного регулирования Российской Федерации и субъектов Федерации, а также установить рамки государственно-властного вмешательства в избирательный процесс.

Третье. Нестабильность законодательства о выборах, постоянные изменения нормативной базы влекут за собой слабое знание участниками избирательного процесса положений действующих нормативных правовых актов, оказывают отрицательное воздействие на профессиональную и правовую культуру организации и проведения выборов и, как следствие, вызывают рост правонарушений в сфере избирательных прав.

Источник опубликования: Красинский В.B. Теоретические основы нормативного правового регулирования организации и проведения выборов в Российской Федерации // Конституционное и муниципальное право. М.: Юристь, 2003. № 1. С.13-16

${ }^{1}$ Теория государства и права. Учебник для юридических вузов и факультетов. Под ред. М.В.Корельского и В.Д.Перевалова. М.: Издательская группа Инфра М-Норма, 1997. С. 256; Мордовеи А.С. Теория государства и права. М. 1997. С. 622.

${ }^{2}$ Словарь русского языка: В 4-х т./АН СССР, Институт русского языка; Под ред. А.П. Евгеньевой. - 3-е изд., стереотип. - М.: Русский язык, 1987. Т. 3. С.695.

${ }^{3}$ Там же. Т. 3. С.725.

${ }^{4}$ Комаров С.А. Общая теория государства и права. М. 1999. С. 60

${ }^{5}$ Cырых B.M. Теория государства и права. М.: Юридический Дом Юстиц-информ, 2001. С. 76.

6 В теории права в качестве правовых средств выступают нормы права, правоприменительные акты, договоры, юридические факты, субъективные права, юридические обязанности, запреты, льготы, поощрения, наказания и т.д. См.: Алексеев С.С. Правовые средства: постановка проблемы, понятие, классификация // Советское государство и право. 1987. № 6. С. 14; Малько А.B. Правовые средства: вопросы теории и практики // Журнал российского права. 1998. № 8. С. 66-77.

7 Сапун В.А. Инструментальная теория права в юридической науке // Современное государство и право: Вопросы теории и истории. Владивосток, 1992. С.18.

${ }^{8}$ Пункт 19 статьи 2 Федерального закона от 12 июня 2002 года № 67-Ф3 «Об основных гарантиях избирательных прав и права на участие в референдуме граждан Российской Федерации» // С3 РФ. 2002. № 24, ст. 2253.

9 Избирательное право и избирательный процесс в Российской Федерации. Учебник для вузов. Под ред. А.В.Иванченко. М.: Издательство НОРМА, 1999. С. 259.

${ }^{10}$ См.: Пункты 22, 23 статьи 2 Федерального закона от 12 июня 2002 года № 67-Ф3 «Об основных гарантиях избирательных прав и права на участие в референдуме граждан Российской Федерации» // С3 РФ. 2002. № 24, ст. 2253.

${ }^{11}$ Содержание - определенным образом упорядоченная совокупность элементов и процессов, образующих предмет или явление. Форма - способ существования и выражения этого содержания. Философский словарь/ Под ред. И.Т.Фролова. - 7 -е изд., перераб. и доп. М.:Республика, 2001. С. 519.

12 Тезисы докладов Международной конференции «Криминологическая и правовая культура общества: проблемы формирования и влияния на правопорядок» (Москва, 26-27 сентября 
2002 года). В сб.: Проблемы правовой и криминологической культуры борьбы с преступностью. - М.: Российская криминологическая ассоциация, 2002. 108 с. 